\title{
НЕКОТОРЫЕ АСПЕКТЫ ЭТИОЛОГИИ, ПАТОГЕНЕЗА И КЛИНИЧЕСКИХ ПРОЯВЛЕНИЙ НОВОЙ КОРОНАВИРУСНОЙ ИНФЕКЦИИ (обзор литературы)
}

\author{
Л.А. Ермакова, А.Г. Суладзе, Н.Н. Долгова, О.С. Думбадзе, Т.И. Твердохлебова \\ ФБУН «Ростовский научно-исследовательский институт микробиологии и \\ паразитологии» Роспотребнадзора, г. Ростов-на-Дону
}

Резюме. В настоящей работе представлен обзор данных литературы, посвященных новой коронавирусной инфекции (COVID-19).

Цель данного обзора - анализ и обобщение результатов некоторых опубликованных исследований по вопросам этиологии, патогенеза и клинических проявлений различных форм COVID-19, а также изменений, регистрирующихся при лабораторном и инструментальном обследовании больных различными формами течения данной инфекции.

Благодаря способности к стремительной мутации, которой отличаются все микст - вирусы, SARS-CoV-2 стал высококонтагиозным антропонозом, способным вызывать заболевание человека. Высокая восприимчивость организма человека к новому коронавирусу, разнообразие механизмов и путей передачи, полиморфность клинической симптоматики от признаков поражения дыхательных путей, общетоксического синдрома до диспептических явлений, в сочетании со значительной долей больных с легкими и бессимптомными формами COVID-19, являющимися при этом эффективными источниками заражения населения, привели к развитию текущей пандемии.

В настоящее время во всем мире для борьбы с текущей пандемией международные органы общественного здравоохранения и научное сообщество практически ежедневно актуализируют информацию об особенностях клинического течения, повышают достоверность существующих методов диагностики и эффективность способов лечения COVID-19, а также выявляют предикторы его неблагоприятного прогноза.

Информированность специалистов практического здравоохранения об особенностях эпидемиологии и клинических проявлениях новой коронавирусной инфекции имеет решающее значение в снижении заболеваемости населения и прогнозировании развития тяжелых форм COVID19 и, соответственно в уменьшении количества летальных исходов. 
Ключевые слова: новая коронавирусная инфекция (COVID-19), этиология, патогенез, клинические особенности, лабораторные и инструментальные данные.

\section{Введение.}

По данным на 18 августа 2020 года зарегистрировано 22067 280случаев COVID-19 в 213 странах мира, из них более 775000 завершились летальным исходом.

Пандемия COVID-19 представляет собой серьезную проблему для властей, каждого человека и общества в целом. Глобальное распространение новой коронавирусной инфекции 2019 года (COVID-19) оказалось серьезным вызовом для общественного здравоохранения во всем мире.

Особенностью новой коронавирусной инфекции является значительное число бессимптомных форм (до 90\%), что осложняет проведение адекватных противоэпидемических мероприятий.

Клинически COVID-19 отличается полиморфностью симптомов, чаще проявляется поражением верхних и нижних дыхательных путей от легких форм, манифестирующихся затрудненным носовым дыханием и аносмией, до стремительно развивающейся вирусной пневмонии, вплоть до развития острого респираторного дистресс-синдрома. Также описаны случаи осложнений в форме тяжелой виремии с развитием полиорганной недостаточности [1].

В настоящем обзоре представлены результаты анализа литературных данных по вопросам этиологии, патогенеза и клинических проявлений COVID-19.

Цель. Дать оценку современному пониманию нового коронавируса SARS$\mathrm{CoV}-2$ и заболевания, которое он вызывает.

Этиология. COVID-19 - высококонтагиозное инфекционное заболевание, вызываемое $\beta$-коронавирусом 2 (SARS-CoV-2), который был впервые выделен и идентифицирован у пациентов, заразившихся на рынке морепродуктов в городе Ухань провинции Хубэй Китайской Народной Республики, в декабре 2019 года [2].

Существует четыре основных подгруппы коронавирусов ( $\alpha, \beta, \gamma$ и $\delta)$. В группу $\alpha$-коронавирусов входят шесть видов, включая патогены человека Cov229E и CoV-HKU1. В группу $\beta$-коронавирусов, к которой относится SARS$\mathrm{CoV}-2$, также входят патогенные для человека CoV-OC43, SARS-CoV и MERS$\mathrm{CoV}[3,4]$. Подобно коронавирусам, вызывающим атипичную пневмонию (SARS-CoV) $[5,6]$ и ближневосточный респираторный синдром (MERS-CoV) [7], по мнению исследователей, SARS-CoV-2 является микст - вирусом [8] . PHK-содержащий вирус SARS-CoV-2 имеет диаметр 60-140 нм. Анализ нуклеотидных последовательностей генома SARS-CoV-2 выявил его идентичность с SARS-CoV на 79,5\% и с геномом вируса RaTG12, выделенного 
из летучей мыши (Rhinolophus affinis), обитающей в провинции Юньнань, Китай на 93,1\% [8,9]. Данные результаты свидетельствуют в пользу того, что SARS-CoV-2 может происходить из вируса, который является эндемичным для указанного вида летучих мышей. Сравнительный геномный анализ нуклеотидных последовательностей, идентифицированных в белке $\mathrm{S}$ коронавируса, выделенного из панголина (Order, Pholidota; Family, Manidae), показал, что эти млекопитающие, скорее всего, были промежуточными хозяевами для межвидовой передачи [10,11].

Благодаря способности к стремительной мутации, которой отличаются все микст - вирусы, SARS-CoV-2 приобрел способность не только вызывать заболевание человека, но и передаваться от человека к человеку. В настоящее время COVID-19 уже не зоонозная, а антропонозная инфекция, которая преимущественно распространяется путем передачи от человека человеку [12].

По данным литературы, инфекционный процесс реализуется, преимущественно, воздушно-капельным и контактно-бытовым путями передачи возбудителя, что способствует пандемическому распространению SARS-CoV-2. Уровень летальности при COVID-19 (2-3\%) значительно ниже такового при SARS (около 10\%) и MERS (около 40\%), однако высокая восприимчивость организма человека и разнообразие путей передачи вируса привели к возникновению пандемии.

Было установлено, что как при инфекции SARS-CoV, как и при инфекции SARS-CoV-2, основой патогенеза тяжелых форм COVID-19 является способность вируса проникать в клетки легких с помощью белка S, который связывается с ангиотензинпревращающим ферментом 2 (ACE2) пневмоцитов II типа [13]. Таким образом, белок $\mathrm{S}$ играет центральную роль в передаче и развитии COVID-19. Белок S коронавируса включает два основных домена: домен S1 на N-конце белка опосредует связывание с ACE2, а C-концевой домен S2 способствует слиянию вирусной мембраны с клеточной мембраной клеткихозяина [14].

Нуклеотидные последовательности белка S SARS-CoV-2 имеют только ограниченную гомологию с SARS-CoV; степень идентичности довольно низкая в домене S1 (64\%) и сравнительно высокая в домене S2 (до 90\%). В пределах домена S1 N-концевая часть менее консервативна (51\%), в то время как субдомен C-концевого RBD имеет относительно высокую степень стабильности (74\%), что позволяет взаимодействовать с одним и тем же рецептором клеточной поверхности ACE2 [15]. Результаты исследований, проведенных рядом ученых [16,17], свидетельствуют о том, что белок S в SARS-CoV-2 имеет аффинность к ACE2 в 10-20 раз выше, чем SARS-CoV, что также подтвердилось данными анализа in silico (с помощью компьютерного моделирования). Возможно именно эта особенность нового коронавируса и 
способствует очевидной легкости, с которой он может передаваться от человека к человеку, однако полученные результаты еще предстоит подтвердить в экспериментах in vitro и in vivo.

\section{Патогенез заболевания}

Патогенез COVID-19 на настоящий момент изучен недостаточно, однако ряд авторов предполагают, что он аналогичен SARS. Коронавирусы оказывают цитопатическое воздействие на эпителиальные клетки дыхательных путей и альвеоциты человека. Подобно тому, что наблюдалось при инфекции, вызываемой SARS-CoV, важную роль в патогенезе COVID-19 играют выраженные иммунологические реакции, особенно у лиц с неблагоприятным преморбидным фоном. Внедрение SARS-CoV-2 в альвеоциты вызывает местное воспаление и способствует выделению цитокинов, включая трансформирующий фактор роста- $\beta 1$ (TGF- $\beta 1)$, фактор некроза опухолей- $\alpha$

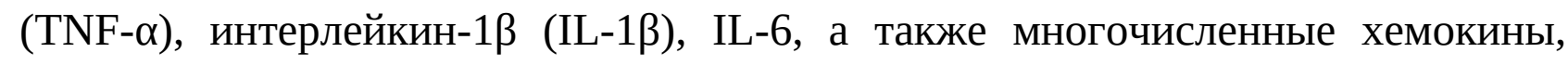
которые служат для инициации циркулирующих лейкоцитов $[18,19]$.

При тяжелых формах COVID-19 последующий воспалительный каскад может привести к «цитокиновому шторму» [18]. Считается, что «цитокиновый шторм» является ключевым фактором, вызывающим как острый респираторный дистресс - синдром (ОРДС), так и полиорганную недостаточность [20].

Неблагоприятным прогностическим признаком тяжелой формы COVID19 является лимфопения периферической крови. Это, скорее, функциональное явление, возникающее за счет активной пролиферации лимфоцитов в инфицированную вирусом ткань легкого [21]. Несмотря на снижение общего количества лимфоцитов, в периферической крови значительно возрастает доля активированных HLA-DR + CD38 + T-клеток. Аналогичным образом наблюдается увеличение доли клеток CCR4 + CCR6 + Th17, подгруппы CD4 + Т-лимфоцитов с цитотоксическими функциями, аналогичными тем, которые характерны для CD8 + Т-лимфоцитов [21]. Как таковые, эти первичные данные предполагают критическую роль Т-клеток в модулировании воспалительного ответа легких, связанного с COVID-19.

В соответствии с новыми данными важное значение имеет возникновение коагулопатии, связанной с COVID-19 [22]. Более того, многофакторный регрессионный анализ в когортах COVID-19 показал, по данным авторов из Китайской Народной Республики, что повышенные уровни в плазме D-димеров деградации фибрина являются независимым биомаркером неблагоприятного прогноза COVID-19 [23]. В поддержку гипотезы о том, что активация коагуляции играет важную роль в патогенезе COVID-19, также описаны данные аутопсий, результаты которых выявили заметные патологические 
изменения, непосредственно затрагивающие капиллярную сеть легких, включая диссеминированные микротромбы и значительный геморрагический некроз [24,25]. Данные авторов [26,27] свидетельствуют о том, что тяжелые формы COVID-19 протекают с высоким риском развития тромбоза глубоких вен и тромбоэмболии легочной артерии.

Интерес представляют результаты исследования секционного материала от больных новой коронавирусной инфекцией. Международная группа специалистов из стран Латинской Америки и Европы представила обзор и анализ литературных данных, имеющихся в настоящее время в свободном доступе, посвященных особенностям морфологических изменений в органах и системах у больных COVID-19 [28]. На основании проведенного анализа исследователи установили, что значимые изменения при данной инфекции отмечаются практически во всех органах и системах (легкие, сердце, почки, система кровообращения, центральная нервная система, гемолимфатическая система). Из них наиболее часто регистрируются значимые гистологические находки в легких: диффузное альвеолярное поражение на разных стадиях, в первую очередь, экссудативные процессы, которые были отмечены в 22 из 27 исследований, воспалительные изменения - в 21 исследовании и тромбоэмболические - в 11 исследованиях.

В других органах регистрировались: очаговый лимфоцитарный миокардит, острое повреждение почечных канальцев, микротромбозы сосудов центральной нервной системы с исходами в форме ишемического некроза, острого геморрагического инфаркта; гемофагоцитарный синдром в лимфатических узлах и костном мозге, а также тромбоз глубоких вен, осложненный легочной тромбоэмболией. Результаты исследования биопсийного и секционного материала позволили обосновать основные гипотезы патогенеза COVID-19, а именно: патологический иммунный ответ на вирус с гипервоспалительной реакцией на вирус и аномальную коагуляцию, которая развивается, возможно, за счет непосредственного повреждения вирусом эндотелиальных клеток, а, возможно, является вторичной за счет патологических иммунных реакций.

\section{Клинические особенности}

В значительном числе опубликованных исследований авторами отмечены различные степени клинической тяжести COVID-19 [19,29-35]. Инкубационный период колеблется от 0 до 24 дней, в среднем 5-7 дней [30]. K инфекции восприимчивы лица любого возраста, а также новорожденные и беременные женщины. У большинства пациентов заболевание протекает в бессимптомной, легкой и среднетяжёлой форме. Наиболее распространенными симптомами являются лихорадка, сухой кашель, слабость. Симптомы 
поражения верхних дыхательных путей могут проявляться аносмией, заложенностью носа, болью и першением в горле, сухим, реже влажным кашлем, одышкой, болями в грудной клетке. Кроме этого, больные предъявляют жалобы на слабость, головные боли и миалгию. Имеются сведения о нарушениях функции желудочно-кишечного тракта: боли в животе, диарея у детей и подростков [36]. Приблизительно у 20\% пациентов с COVID19 развивается тяжелое респираторное заболевание со средним показателем летальности около 2,3\%. В клинической картине больных с тяжелым течением COVID-19 наиболее часто регистрируется лихорадка, сухой кашель, одышка и двусторонние легочные инфильтраты при инструментальных исследованиях органов грудной клетки. Осложнениями COVID-19 являются ОРДС, дыхательная недостаточность, поражение печени, острое повреждение миокарда, острое повреждение почек, септический шок и полиорганная недостаточность. Факторы риска прогрессирования заболевания еще не установлены. Тем не менее, предварительные данные свидетельствуют о том, что тяжелые заболевания чаще встречаются у лиц старшего возраста, мужского пола и лиц с сопутствующими заболеваниями. В исследовании, включавшем 1099 пациентов с подтвержденным COVID-19, было отмечено, что около 23\% больных страдали одним или несколькими хроническими заболеваниями, в том числе: хроническая обструктивная болезнь легких (1,1\%), артериальная гипертензия (14,9\%), сахарный диабет (7,4\%), коронарокардиосклероз (2,5\%), гепатит В и цирроз печени (2,3\%) [36].

Данные обследования более 70000 пациентов с COVID-19, показали, что более 80\% лиц, погибших от данной инфекции, были старше 60 лет и более 75\% имели хронические заболевания сердца, легких, почек, сахарный диабет, злокачественные новообразования [37].

В когортном исследовании, включившем 62 пациента, в китайской провинции Чжэцзян, только у одного больного COVID-19 развился OРДС, при этом не было зарегистрировано ни одного летального исхода [33].

Внимания заслуживает работа исследователей из Южной Кореи, посвященная анализу клинических данных больных с легкими и бессимптомными формами COVID-19 [38]. В феврале 2020 г. в Южной Корее была выявлена вспышка COVID-19 в религиозной общине Shincheonji, где в результате лабораторных исследований был подтвержден 3081 случай COVID19. Лица с лабораторно подтвержденным диагнозом, не имевшие клинических проявлений инфекции, с незначительными симптомами и с неотягощенным преморбидным фоном находились в изоляции не в условиях больничного стационара, а в специально организованном обсервационном учреждении. Это позволило определить распространенность бессимптомных форм в данной вспышке и дать клиническую характеристику легкой формы COVID-19. 
Исследование проводили на основании мониторинга 213 больных. Из них 41 оставались бессимптомными до поступления. При анализе клинических данных обследования 172 пациентов с манифестным течением COVID-19 наиболее распространенным симптомом был кашель (40,1\%; 69/172), гипосмия (39,5\%; 68/172) и заложенность носа (34,3\%; 59/172). Из 68 человек с устойчивой потерей или снижением обоняния у 61 (90\%) были сопутствующие симптомы, такие как гипогевзия, заложенность носа или ринорея. Лихорадка (> 37,5 C) была отмечена только у 20 (11,6\%) человек.

Интересно, что гипосмия была самым частым признаком инфекции у больных с легкой формой COVID-19. Симптом устойчивой потери или снижения обоняния нередок также и при многих других острых респираторных вирусных инфекциях и обусловлен обонятельной дисфункцией, развивающейся за счет повреждения вирусами эпителия [39], однако для определения специфичности этого симптома при COVID-19 необходимы дальнейшие исследования.

Наличие бессимптомных случаев COVID-19 было отмечено в ранних сообщениях о вспышке [37], а в большом исследовании, проведенном при обследовании 72314 больных COVID-19, сообщалось, что только у $1 \%$ пациентов отмечалось бессимптомное течение болезни при положительном результате ПЦР теста, при этом доля легких форм составила 81\%, среднетяжелых - 14\%, тяжелых - 5\% [45]. Однако основная часть данной выборки была представлена больными из провинции Хубэй, где острая нехватка ресурсов здравоохранения, очевидно, привела к смещению выборки в сторону уменьшения лиц с легкими формами COVID-19 и не отражала реальное число бессимптомных форм. По данным другого исследования, проведенного группой ученых из Южной Кореи [38], бессимптомные формы заболевания составили не менее $20 \%$.

По мнению ряда исследователей $[40,41,42,43,44]$, лица с бессимптомным течением COVID-19 выделяют жизнеспособный SARS-CoV-2, что позволяет предположить возникновение ряда кластеров новой коронавирусной инфекции в результате заражения от больных легкими и бессимптомными формами.

Было установлено, что основными клиническими симптомами больных COVID - 19 были повышение температуры (88,5\%), кашель (68,6\%), миалгия или усталость (35,8\%), отхождение мокроты (28,2\%), одышка $(21,9 \%)$. В дополнение к общим респираторным симптомам у некоторых пациентов были также выявлены симптомы головной боли или головокружения (12,1\%), диареи (4,8\%), тошноты и рвоты (3,9\%) Следует отметить, что у 30\% больных MERS также регистрируются диспепсические явления, в частности - диарея. По данным исследования специалистов из KHP [45], SARS-CoV-2 обнаруживался в образцах стула пациентов с абдоминальными симптомами. Поэтому, кроме 
больных с патологией дыхательной системы, в качестве основного симптома, внимания требуют также пациенты с признаками общей интоксикации (головная боль, головокружение) и диспептическими явлениями (диарея, анорексия, тошнота и рвота).

В когортном исследовании Diangeng $\mathrm{Li}$ et al. [46] авторами было обнаружено, что SARS-CoV-2 может присутствовать в сперме пациентов с COVID-19. В исследовании приняли участие 38 мужчин фертильного возраста, из которых 23 (60,5\%) пациента были в периоде реконвалесценции, а 15 (39,5\%) - в острой стадии COVID-19. Результаты тестирования спермы пациентов показали, что 6 пациентов (15,8\%) имели положительные результаты на SARS-CoV-2, в том числе 4 из 15 пациентов (26,7\%) находились в острой стадии инфекции и 2 - из 23 (8,7\%) реконвалесцентов. При этом не было установлено существенной зависимости от возраста, длительности течения новой коронавирусной инфекции, а также наличия заболевания мочевыводящих путей в анамнезе. Авторы не исключают, что наличие вирусов в сперме может быть весьма распространенным явлением, имеющим важное эпидемиологическое значение, поскольку выживание SARS-CoV-2 в сперме выздоравливающего пациента обусловливает вероятность заражения.

В апреле 2020 года группа ученых из Испании представила подробное описание синдрома сыпи на примере 375 случаев COVID-19 [47]. Авторами описаны 5 групп высыпаний, которые регистрировались у пациентов с различной тяжестью течения болезни. У 19 \% больных отмечались участки эритемы-отека с отдельными пузырьками или пустулами в области верхних и нижних конечностей; у $19 \%$ регистрировалась крапивница; у 9\% везикулезная сыпь. Наиболее часто (47\%) наблюдались макуло-папулезные высыпания, значительно реже - некротические высыпания (6\%), очевидно обусловленные расстройствами гемостаза.

\section{Лабораторные данные у больных COVID-19}

При исследовании общего анализа крови у больных COVID-19 нередко регистрируется лимфопения при нормальном количестве лейкоцитов. При легких и среднетяжелых формах количество лейкоцитов периферической крови остается в пределах нормы, изредка отмечается незначительная лейкопения. У больных с тяжелым течением коронавирусной инфекции регистрируется лейкоцитоз. Показатели системного воспаления, включая сывороточные уровни ферритина и С-реактивного белка (СРБ), а также скорость оседания эритроцитов (СОЭ), могут быть повышены за счет высокого уровня циркулирующих провоспалительных цитокинов и хемокинов. У пациентов с внелегочными системными осложнениями могут отмечаться повышение уровня аланинаминотрансферазы (АЛТ), аспартатаминотрансферазы (АСТ), тропонина и / или креатинина в сыворотке крови. 
По данным некоторых исследователей, лимфоцитопения регистрировалась у $64,5 \%$ больных, повышение СРБ - у 44,3\%, увеличение лактатдегидрогеназы (ЛДГ) у 28,3\% и лейкоцитопения в 29,4\% случаев[36]. B работе Long, Q., et al. [48] отмечено, что при обследовании 37 больных с бессимптомной формой COVID-19 показатели крови были в пределах нормы, только у 3 пациентов регистрировалась лимфопения и у 1 - тромбоцитопения; в 6 случаях наблюдался повышенный уровень аланинаминотрансферазы, а повышение уровня С-реактивного белка было отмечено у 11 лиц. Также в данном исследовании отражена роль методов компьютерной томографии (KT) в своевременной диагностике COVID-19. По данным авторов, при поступлении КT выявляла очаговые изменения по типу «матового стекла» у 11 бессимптомных пациентов (29,7\%) и диффузную консолидацию у 10 человек (27,0\%). Одностороннее поражение легких регистрировалось у 66,7\%, двухстороннее - у 33,3\% больных. Признаки поражения легких при КТ грудной клетки отсутствовали у 16 больных (43,2\%). Однако через 5 дней после поступления в стационар у 5 пациентов были выявлены очаговые изменения. У лиц с бессимптомным течением болезни отсутствовали признаки плеврального выпота, увеличения лимфатических узлов, характерные для тяжелого течения COVID-19.

В первых публикациях по результатам инструментального обследования больных новой коронавирусной инфекцией авторы отмечали наличие изменений в легких у 100\% больных в г. Ухане и примерно у $80 \%$ - в когортных исследованиях, выполненных за его пределами. Как правило, ранние признаки поражения легких при КТ органов грудной клетки были единичными или множественными и представлены в виде ограниченных участков затемнения с интерстициальными изменениями, обычно расположенными по периферии легочных полей, близко к плевре. Также регистрировались изменения в бронхах и уплотнения сосудистых стенок. Признаки поражения легких часто были двухсторонними и нередко прогрессировали до появления множественных очагов по типу «матового стекла» с минимальным плевральным выпотом или без него. При тяжелом или крайне тяжелом течении COVID-19 при KT органов грудной клетки регистрировались мультилобулярные и диффузные инфильтраты, которые быстро развились до полной консолидации легких [36].

Интерес представляет работа исследователей из Китая [49], проанализировавших результаты КТ органов грудной клетки 21 больного COVID-19. Было установлено, что в 18 из 21 случая (86 \%) регистрировались изменения, затрагивающие, по крайней мере, одну долю легких. Только у трех пациентов при КТ грудной клетки не было выявлено признаков поражения легочной ткани. Авторы отмечают, что изменения в легких по типу «матового 
стекла» наблюдалось у 12 пациентов (57 \%), а участки консолидации - у шести (29 \%). При этом более, чем у 71\% больных поражались более чем две доли легких, а поражение обоих лёгких было зарегистрировано у16 из 21 больного (76 \%). При повторном обследовании уплотнения округлой формы обнаруживали у 7 из 21 пациента (33\%), уплотнения с преимущественно линейным паттерном у 3 из 21 пациента (14 \%) и симптом «булыжной мостовой» - у 4 из 21 пациента, (19\%). Также у 7 из 21 больного регистрировалось распространение инфильтрации ткани лёгкого на периферию (33\%).

Таким образом, данное исследование демонстрирует важное значение инструментальных методов для ранней диагностики новой коронавирусной инфекции. Однако следует отметить, что KT-признаки SARS-CoV-2 сходны с таковыми при других вирусных пневмониях, в первую очередь, SARS и MERS.

\section{Заключение.}

Недостаточный уровень знаний о новой коронавирусной инфекции на ранних стадиях болезни, отсутствие доказанных эффективных средств этиотропной терапии и высокая контагиозность вируса привели к резкому увеличению числа больных, пандемическому распространению инфекции, что повлекло за собой дефицит медицинских ресурсов.

В настоящее время во всем мире для борьбы с текущей пандемией органы общественного здравоохранения практически ежедневно актуализируют мероприятия по предупреждению распространения новой коронавирусной инфекции, информируют о новых данных, касающихся особенностей клинического течения, эффективности способов лечения COVID-19 и предикторов его неблагоприятного прогноза.

Ограниченное количество и качество проведенных исследований обусловливают необходимость более обширного и широкомасштабного изучения клинических и параклинических аспектов данной инфекции.

Сортировка пациентов с подозрением на COVID-19 от других больных врачами скорой помощи, приемных отделений и амбулаторнополиклинической службы, основанная на знаниях особенностей эпидемиологии и клинических проявлений новой коронавирусной инфекции, имеет решающее значение для предотвращения потенциальной вспышки в условиях медицинских организаций.

Список литературы.

1. Di Liua, Qi. Wang, H. Zhang, L. Cui, et al. Viral sepsis is a complication in patients with Novel Corona Virus Disease (COVID-19). Medicine in Drug Discovery https://www.sciencedirect.com/science/article/pii/S2590098620300440?via\%3Dihub 
2. Zhu N, Zhang DY, Wang WL, et al., 2020. A novel coronavirus from patients with pneumonia in China, 2019. N. Engl J Med, 382(8):727-733. ).

3. King AMQ, Adams MJ, Carstens EB, et al., 2012. Virus Taxonomy. Ninth Report of the International Committee on Taxonomy of Viruses. Elsevier, San Diego, USA, p.770-783.

4. Lefkowitz EJ, Dempsey DM, He ndrickson RC, et al., 2018. Virus taxonomy: the database of the International Committee on Taxonomy of Viruses (ICTV). Nucleic Acids Res, 46(D1):D708-D717.

5. Drosten C, Günther S, Preiser W, et al., 2003. Identification of a novel coronavirus in patients with severe acute respiratory syndrome. N Engl J Med, 348(20):19671976. https://doi.org/10.1056/NEJMoa030747.

6. Ksiazek TG, Erdman D, Goldsmith CS, et al., 2003. A novel coronavirus associated with severe acute respiratory syndrome. N Engl J Med, 348(20):19531966. https://doi.org/10.1056/NEJMoa030781

7. Zaki AM, van Boheemen S, Bestebroer TM, et al., 2012. Isolation of a novel coronavirus from a man with pneumonia in Saudi Arabia. N Engl J Med, 367(19):1814-1820. https://doi.org/10.1056/NEJMoa1211721.

8. Chan JFW, Kok KH, Zhu Z, et al., 2020b. Genomic characterization of the 2019 novel human-pathogenic coronavirus isolated from a patient with atypical pneumonia after visiting Wuhan. Emerg Microbes Infect, 9(1):221-236.

https://doi.org/10.1080/22221751.2020.1719902.

9. Zhou P, Yang XL, Wang XG, et al., 2020b. A pneumonia outbreak associated with a new coronavirus of probable bat origin. Nature , 579(7798):270-273.

https://doi.org/10.1038/s41586-020-2012-7.

10. Liu P, Chen W, Chen JP, 2019. Viral metagenomics revealed Sendai virus and coronavirus infection of Malayan Pangolins (Manis javanica). Viruses, 11(11):979. https://doi.org/10.3390/v11110979.

11. Zhang T, Wu QF, Zhang ZG, 2020. Pangolin homology associated with 2019nCoV. bioRxiv, preprint. https://doi.org/10.1101/2020.02.19.950253).

12. V. Oberemok, K. Laikova, K. Yurchenko et al. SARS-CoV-2 will continue to circulate in the human population: an opinion from the point of view of the virus-host relationship. nflammation Research (2020) 69:635-640 https://doi.org/10.1007/s00011-020-01352

13. Gallagher TM, Buchmeier MJ, 2001. Coronavirus spike proteins in viral entry and pathogenesis. Virology, 279(2): 371-374.

https://doi.org/10.1006/viro.2000.0757).

14. Hofmann H, Pöhlmann S, 2004. Cellular entry of the SARS coronavirus. Trends Microbiol, 12 (10) : 466-472. https://doi.org/10.1016/j.tim.2004.08.008). 15. Jaimes JA, André NM, Millet JK, et al., 2020. Structural modeling of 2019novel coronavirus (nCoV) spike protein reveals a proteolytically-sensitive activation 
loop as a distinguishing feature compared to SARS-CoV and related SARS-like coronaviruses. bioRxiv, preprint. https://doi.org/10.1101/2020.02.10.942185).

16. Wrapp D, Wang N, Corbett KS, et al., 2020. Cryo-EM structure of the 2019nCoV spike in the prefusion conformation. Science, 367(6483):1260-1263. https://doi.org/10.1126/science.abb2507.

17. Huang Q, Herrmann A, 2020. Fast assessment of human receptor-binding capability of 2019 novel coronavirus (2019-nCoV). bioRxiv, preprint. https://doi.org/ 10.1101/2020.02.01.930537.

18. Razzaque MS, Taguchi T, 2003. Pulmonary fibrosis: cellular and molecular events. Pathol Int, 53(3):133-145. https://doi.org/10.1046/j.14401827.2003.01446.x).

19. Huang CL, Wang YM, Li XW, et al., 2020. Clinical features of patients infected with 2019 novel coronavirus in Wuhan, China. Lancet, 395(10223):497-506 https://pubmed.ncbi.nlm.nih.gov/31986264/

20. Li C.K., Xu X. (2010) Host Immune Responses to SARS Coronavirus in Humans. In: Lal S. (eds) Molecular Biology of the SARS-Coronavirus. Springer, Berlin, Heidelberg. https://doi.org/10.1007/978-3-642-03683-5 16

21. Xu Z, Shi L, Wang YJ, et al., 2020. Pathological findings of COVID-19 associated with acute respiratory distress syndrome. Lancet Respir Med , 8:420-422. https://doi.org/10.1016/s2213-2600(20)30076-X.

22. Tang N, Li D, Wang X, Sun Z. Abnormal coagulation parameters are associated with poor prognosis in patients with novel coronavirus pneumonia. $\mathrm{J}$ Thromb Haemost. 2020; 18(4): 844- 7.

23. Zhou F, Yu T, Du R, Fan G, Liu Y, Liu Z, et al. Clinical course and risk factors for mortality of adult inpatients with COVID-19 in Wuhan, China: a retrospective cohort study. Lancet. 2020; 395(10229): 1054- 62.

24. Luo W, Yu H, Guo Z, Li X, Sun Y, Li J, et al. Clinical pathology of critical patient with novel coronavirus pneumonia (COVID-19). Preprints. 2020. www.preprints.org.

25. Ding Y, Wang H, Shen H, Li Z, Geng J, Han H, et al. The clinical pathology of severe acute respiratory syndrome (SARS): a report from China. J Pathol. 2003; 200(3): 282-9.

26. Klok FA, Kruip M, van der Meer NJM, Arbous MS, Gommers D, Kant KM, et al. Incidence of thrombotic complications in critically ill ICU patients with COVID19. Thromb Res. 2020. https://doi.org/10.1016/j.thromres.2020.04.013.

27. Cui S, Chen S, Li X, Liu S, Wang F. Prevalence of venous thromboembolism in patients with severe novel coronavirus pneumonia. J Thromb Haemost. 2020. https://doi.org/10.1111/jth.14830). 
28. Walter O.Vasquez-Bonilla, Roberto Orozco, Víctor Argueta, Manuel Sierra. A review of the main 2019 (COVID-19) Human Pathology

https://doi.org/10.1016/j.humpath.2020.07.023).

29. Chen NS, Zhou M, Dong X, et al., 2020. Epidemiological and clinical characteristics of 99 cases of 2019 novel corona-virus pneumonia in Wuhan, China: a descriptive study. Lancet, 395(10223):507-513. https://doi.org/10.1016/s01406736(20)30211-7.

30. Guan WJ, Ni ZY, Hu Y, et al., 2020. Clinical characteristics of coronavirus disease 2019 in China. N Engl J Med, in press.

https://doi.org/10.1056/NEJMoa2002032.

31. Huang CL, Wang YM, Li XW, et al., 2020. Clinical features of patients infected with 2019 novel coronavirus in Wuhan, China. Lancet, 395(10223):497506. https://doi.org/10.1016/s0140-6736(20)30183-5.

32. Wang DW, Hu B, Hu C, et al., 2020. Clinical characteristics of 138 hospitalized patients with 2019 novel coronavirus- infected pneumonia in Wuhan, China. JAMA , 323(11): 1061-1069.

33. Xu XW, Wu XX, Jiang XG, et al., 2020. Clinical findings in a group of patients infected with the 2019 novel corona-virus (SARS-CoV-2) outside of Wuhan, China: retrospective case series. BMJ, 368:m606. https://doi.org/10.1136/bmj.m606. 34. Yang XB, Yu Y, Xu JQ, et al., 2020. Clinical course and outcomes of critically ill patients with SARS-CoV-2 pneumonia in Wuhan, China: a singlecentered, retrospec-tive, observational study. Lancet Respir Med , 8(4):e26. https://doi.org/10.1016/s2213-2600(20)30079-5/

35. Young BE, Ong SWX, Kalimuddin S, et al., 2020. Epidemiologic features and clinical course of patients infected with SARS-CoV-2 in Singapore. JAMA, 323(15):1488- 1494. https://doi.org/10.1001/jama.2020.3204/

36. Yu Shi, Gangwang, Xiao-peng Cai, Jing-wen Deng et al. An overview of COVID-19 J.Biomed Biotechnol 2020 21(5):343-360.

37. Zunyou $\mathrm{Wu}$, et al Characteristics of and Important Lessons From the Coronavirus Disease 2019 (COVID-19) Outbreak in China Summary of a Report of 72314 Cases From the Chinese Center for Disease Control and Prevention JAMA. 2020;323(13):1239-1242. doi:10.1001/jama.2020.2648.

38. KimM.-J. KimS.H. RaJ. LeeS. BaeJ. JungS.-H. Kim. Clinical characteristics of asymptomatic and symptomatic patientswith mild COVID-19 G.-u. / Clinical Microbiology and Infection 26 (2020) 948.e1e948.e3948.e2.

39. Wang JH, Kwon HJ, Jang YJ. Detection of parainfluenza virus 3 in turbinate epithelial cells of postviral olfactory dysfunction patients. Laryngoscope 2007;117:1445 e9. 
40. Chan JFW, Yuan S, Kok KH, Huang L. A familial cluster of pneumonia associated with the 2019 novel coronavirus indicating person-to-person transmission: a study of a family cluster. Lancet 2020;395:514e23.

41. Rothe C, Schunk M, Sothmann P, Bretzel G, Groeschl G, Wallrauch C, et al. Transmission of 2019-nCoV infection from an asymptomatic contact in Ger-many. N Engl J M ed 2020;382:970 e 1.

42. Ping $\mathrm{Yu}$, et al. A familial cluster of infection associated with the 2019 novel coronavirus indicating potential person-to-person transmission during the incubation period. J Infect Dis 2020 May 11;221(11):1757-1761. doi: 10.1093/infdis/jiaa077. 43. Bai Y, Yao L, Wei T, Tian F, Jin DY, Chen L, et al. Presumed asymptomatic carrier transmission of COVID-19. JAMA 2020 Feb 21;323(14):1406-1407. doi: 10.1001/jama.2020.2565.

44. Hoehl S, Berger A, Kortenbusch M, Kortenbusch M, Cinatl J, Bojkova D, et al. Evidence of SARS-CoV-2 infection in returning travelers from Wuhan, China. N Engl J Med. 2020 Mar 26;382(13):1278-1280. doi: 10.1056/NEJMc2001899. Epub 2020 Feb 18.).

45. Yongjian Wua Cheng Guob Lantian Tanga Zhongsi Hong, et al. Prolonged presence of SARS-CoV-2 viral RNA in faecal samples. Lancet Gastroenterol Hepatol Volume 5, Issue 5, May 2020, Pages 434-435 2020Published Online March 19, 2020 https://doi.org/10.1016/S2468-1253(20)30083-2).

46. Diangeng Li, Meiling Jin, Pengtao Bao, et al. Clinical Characteristics and Results of Semen Tests Among Men With Coronavirus Disease 2019 JAMA Netw Open. 2020;3(5):e208292. doi:10.1001/jamanetworkopen.2020.8292.

47. C. Galvan Casas et al. Classification of the cutaneous manifestations of COVID-19: a rapid prospective nationwide consensus study in Spain with 375 cases. British Journal of Dermatology (2020) 183, pp71-77).

48. Long, Q., Tang, X., Shi, Q. et al. Clinical and immunological assessment of asymptomatic SARS-CoV-2 infections. NatMed 26, 2020, 1200-1204 (2020). https:// doi.org/10.1038/s41591-020-0965-6)

49. Michael Chung, MD • Adam Bernheim, MD • Xueyan Mei, MS • Ning Zhang, MDetal, CT Imaging Features of 2019 Novel Coronavirus (2019nCoV)Radiology 2020; 295:202-207 https://doi.org/10.1148/radiol.2020200230 